\title{
Aircraft Landing Gear Simulation and Analysis ${ }^{1}$
}

\author{
Derek Morrison $^{2}$, Gregory Neff ${ }^{3}$ and Mohammad Zahraee ${ }^{4}$
}

\begin{abstract}
A computer aided graphical synthesis was undertaken to understand the kinematics of a nose wheel landing gear mechanism such as that on the Lockheed F-16 using Working Model software. The mobility of the design was verified by computer animation.
\end{abstract}

To contrast the nose gear kinematic simulation, the main landing gear located under the wing of a light weight aircraft such as the Berkut (Ber-koot) was also studied. The Berkut is the product of Experimental Aviation, Inc. (E.A.I) located in Santa Monica, California. This plane was selected because it is representative of the growing market of kit and light weight general aviation aircraft in the 1,000 to 2,000 pound weight range. In this weight class, the Solid-Spring landing gear can be used instead of the oleoshock-strut type used in the F-16.

Computer modeling and finite element analysis are explored to analyze stresses developed while landing at normal sink rates.

The deflections of the main spring gear are calculated and the internal stresses evaluated utilizing the finite element program Stardyne (Research Engineers, Inc.). The results of the modeling and simulation are discussed in this paper.

\section{Introduction}

Mechanism kinematics is a very important area in the design of aircraft landing gear. Gear design largely deals with links that make up the geometry of the landing gear and their spatial relationships. The geometry and kinematics of the gear are functions of the aircraft using the gear. Very seldom can any one kinematic design be used for several different aircraft since the design is a function of the individual aircraft's need, i.e., weight, space, volume, aircraft's mission, such as fighter, transport passenger, cargo, etc. Also of importance in the design of aircraft landing gear is the structure. The gear must be able to withstand the shocks of landing and taxiing. A collapse of a landing gear during the landing roll can have devastating effects on the aircraft. This paper seeks to investigate the methods used in the design of landing gear, with an introduction to the kinematics of landing gear design and a detailed structural analyses of a light weight $2000 \mathrm{lb}$ aircraft's main gear.

\section{Analysis}

In this paper two analysis were performed. The first was the kinematic evaluation of a front nose gear such as the Lockheed F-16. The second analysis was a structural study of a main gear for a light weight aircraft such as the Berkut (see figure 3 and 4). The contrasting aircraft and their

\footnotetext{
${ }^{1}$ Sponsored by the Allied Signal/ McNair Summer Undergraduate Research Internship, 1995.

${ }^{2}$ McNair scholar, Mailing address: 9546 South Indiana, Chicago, IL 60628.

${ }_{3}^{3}$ Mailing address: MET Program, Purdue University Calumet, Hammond, IN 46323-2094, e-mail: gneff@purdue.edu, phone: (219) 989-2465.

${ }^{4}$ Mailing address: Purdue University Calumet, Hammond, IN 46323-2094, e-mail: zahraee@ calumet.purdue.edu, phone: (219) $989-2464$.
} 
gears were chosen because, the F-16 nose gear typified the use of landing gear which needed to be retracted in tight spaces and showed economical use of linkages. On the other hand, the Berkut with it's simple leaf spring gear was a good starting point for the evaluation of landing gear using hand and finite element computer analysis. Solid elements were used for this analysis. The theory for finite element method is complex and will not be explained here, nor will the theory of kinematics be explained, rather the procedures used to create the models will be discussed along with some of the decisions that were made in creating the models.

The first analysis was performed to understand the F-16 front gear (see Figure 1). The gear was modeled using stick diagrams based on dimensions furnished by Lockheed Martin Tactical Aircraft Systems (Puttman, 1995).

Stick diagrams serve a purpose similar to that of the electrical schematic or circuit diagram, in that they display only the essential skeleton of the mechanism which however embodies the key dimensions that determine the path of the motion. In the case of this analysis, the stick diagram was taken a step further. Basic geometry was drawn to represent the components of the F-16's landing gear, then a kinematic simulation was performed using the student version of Working Model (Knowledge Revolution, 1995), a computer assisted design program that shows the motion in real-time.

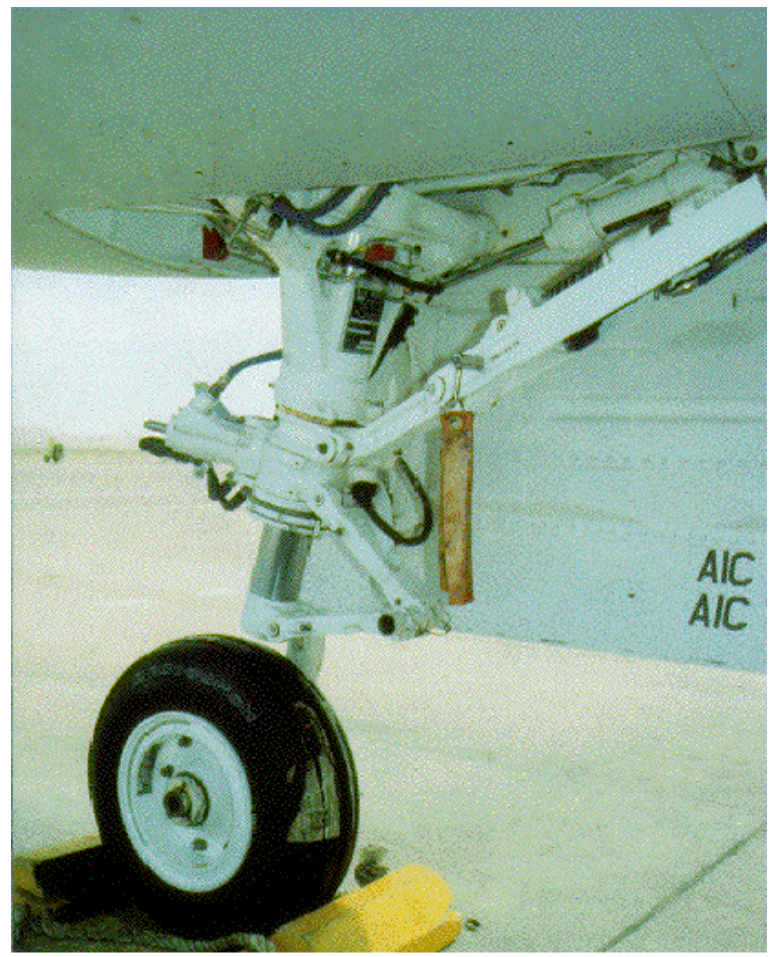

Figure 1
Working Model is an advanced motion simulation package with sophisticated editing capabilities. The program makes it possible to build and analyze dynamic mechanical systems with essentially no programming. The software

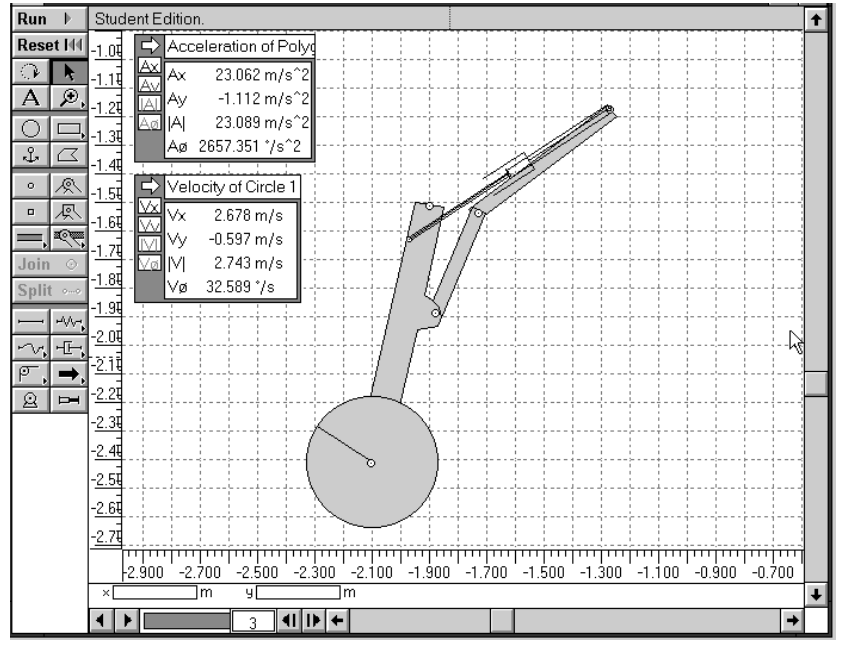

Figure 2a

allows one to design, test, redesign and retest without building a physical model. The windows interface is intuitive and easy to learn. The dynamics engine is physics-based and enables the program to accurately calculate the behavior of even highly complex models. 


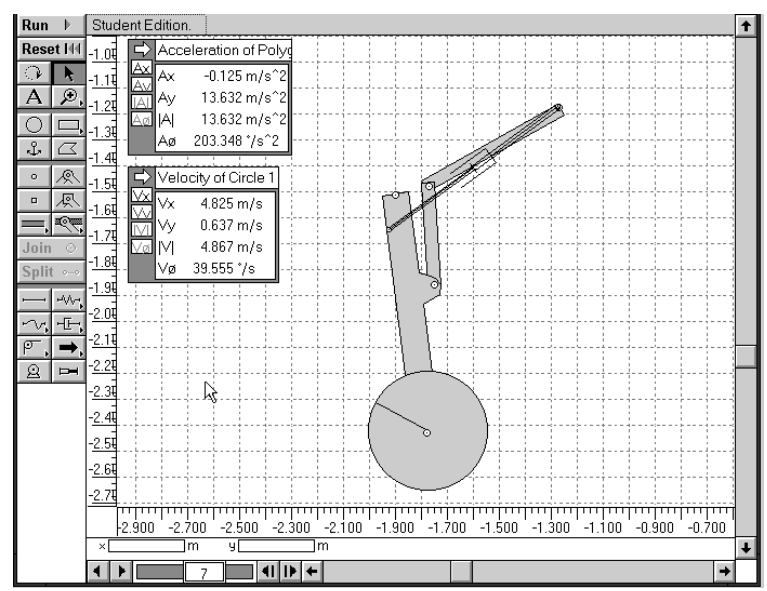

Figure 2b

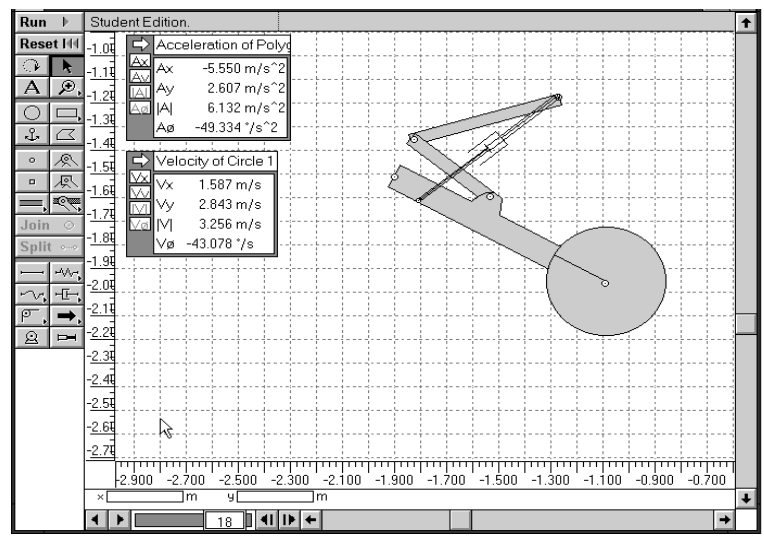

Figure 2d

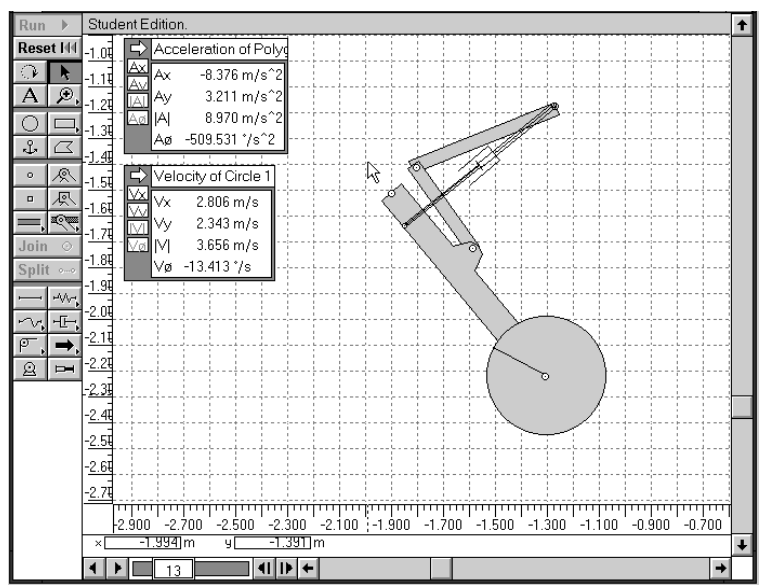

Figure 2c

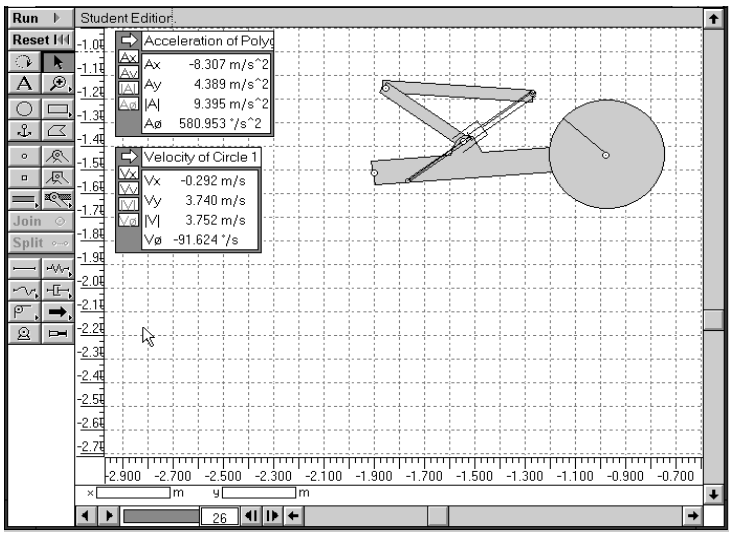

Figure 2e

The general methodology was to use a two dimensional four bar linkage technique for the computer analysis. Iteration produced a design which moved smoothly and freely. Results from the animation are shown in Figures 2a-2e.

The second analysis was the evaluation of the Berkut main landing gear (Figures 3-4). The first step was to draw a model of the landing gear strut in a CAD program from the dimensions supplied by Experimental Aviation, the manufacturer of the Berkut kit (Cox, 1991).

The next step was to calculate the maximum bending stress. This was necessary to validate the finite element results. The detailed finite element analysis results are only as good as the input data; hence the validation. The following data are employed in the Maple V calculations: 
From Stardyne's Material Library

2024-T351 Aluminum

Young's Modulus E $=10,700,000$

Shear Modulus, $G=4,000,000$

Poisson's Ratio, 0.33

Tensile Yield Strength Fy $=42,000$

Compression $\mathrm{Fc}=40,000$

Shear $F s=38,000$

Mass Density $=2.59062 \times 10^{-4}$

These "hand" calculations in Maple follow

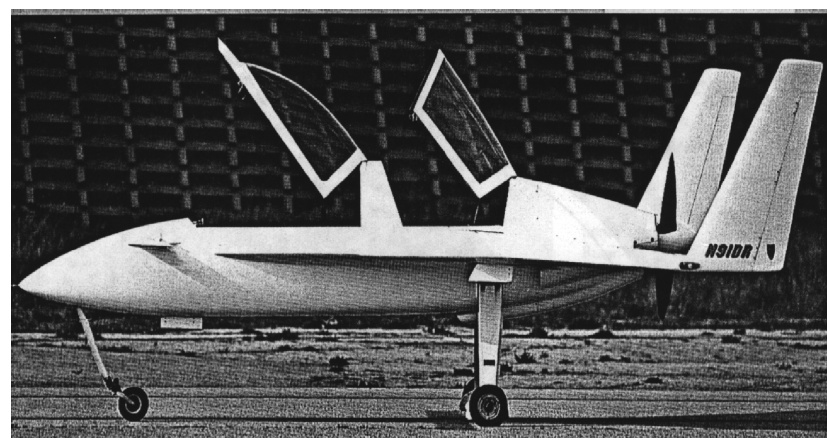

Figure 3

Pazmany (1986) one of the few sources for light aircraft landing gear design available.

The Maple calculations and results:

$$
\begin{aligned}
\mathrm{k} & :=1.5 ; \\
\mathrm{k} & :=1.5
\end{aligned}
$$

Fo: $=21216$;

$$
\text { Fo := } 21216
$$

Fty: $=42000$;

Fty $:=42000$

Fby:=Fty*(1+(Fo/Fty)*(k-1));

Fby $:=52608.00002$

Section Modulus required at root: $\mathrm{I}_{\mathrm{x}} / \mathrm{y}=\mathrm{BM}$

$\mathrm{BM}:=145000$;

$$
\mathrm{BM}:=145000
$$

BM (Bending Moment) comes from the fact that

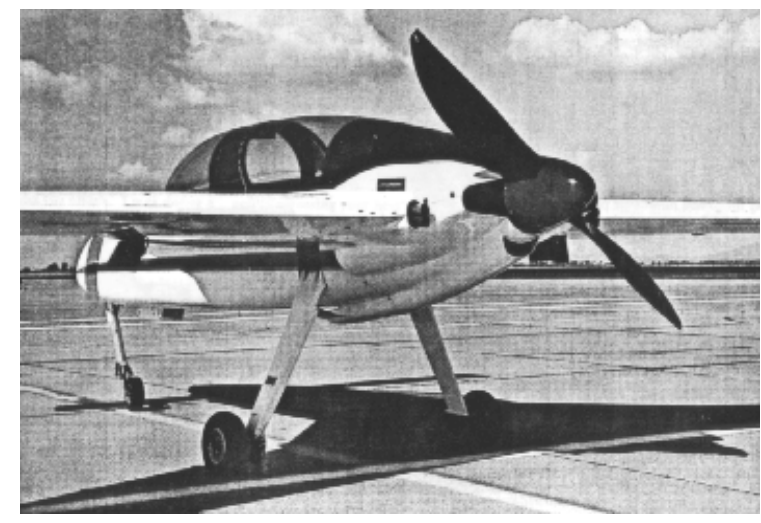

Figure 4

the aircraft's deceleration load is $3453 \mathrm{lb}$ and the strut length is 42 inches

$\mathrm{BM} / \mathrm{Fby}$;

2.756234792

\section{Figure 5}

Actual Section Modulus at Root is $I_{x} / y=b h^{2} / 6$ :

$\mathrm{b}:=7$;

$$
\mathrm{b}:=7
$$

$\mathrm{h}:=1.2$;

$\mathrm{h}:=1.2$

$\left(\mathrm{bh}^{\wedge} 2\right) / 6$;

$$
1.680000000
$$

Bending Stress at Root:

$$
\mathrm{fb}:=\mathrm{BM} /\left(\left(\mathrm{b}^{*} \mathrm{~h}^{\wedge} 2\right) / 6\right) \text {; }
$$$$
\mathrm{fb}:=86309.5237
$$

The next step was to calculate deflection. the

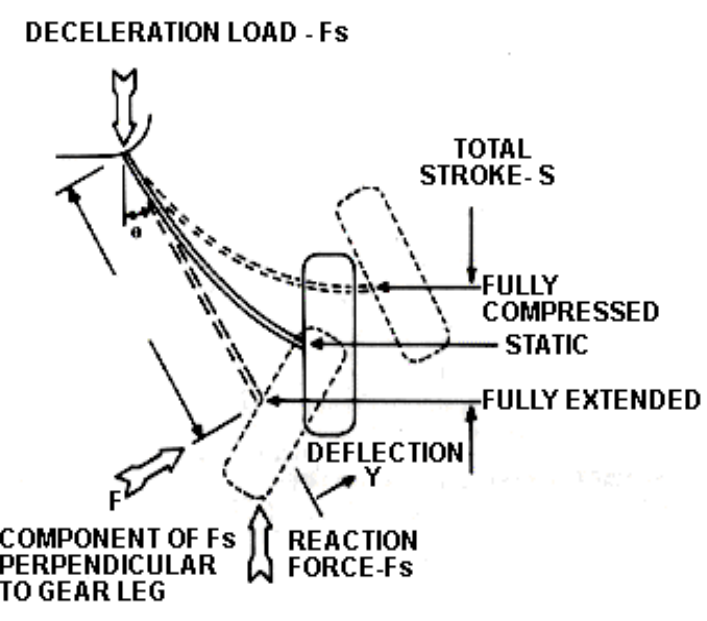

Figure 5 
criterion for deflection first comes from the deceleration load imposed on the strut (see figure 5).

The following calculations determined the deflection on the strut due to landing the aircraft.

FAA design conditions require each main wheel to carry a vertical load at least equal to the airplane gross weight per Federal Aviation Regulations (FAR) 23.473 (g) and FAR 23, Appendix C. This is equivalent to a $2 \mathrm{~g}$ impact load on the main wheel and strut. The following deflection formula will establish acceptable strut cross-section dimensions based upon calculations developed for the Berkut aircraft.

Aluminum leaf spring strut nomenclature.

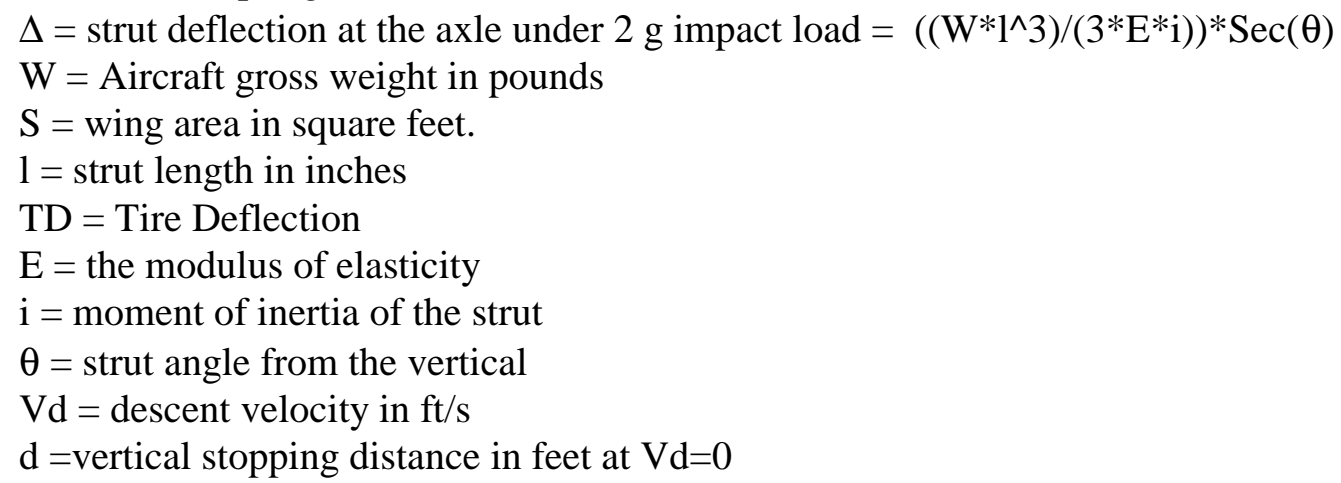

Note: according to Federal Aviation Regulations (FAR) 23.473 (d), the initial descent velocity for landing gear design calculations cannot be less than $4.4(\mathrm{~W} / \mathrm{S})^{\wedge}(1 / 4)$

LVGDIF = landing gear vertical $g$ design inertia factor

VDIF = vertical design inertia factor

$\eta=$ inertia load factor

Note: FAR 23.73 (e) permits a load reduction of $0.67 \mathrm{~g}$ due to wing lift assumed to act during landing, so the landing gear design load factor $(\mathrm{LDLF})=\eta-0.67$

Looking at the formula it appears that the moment of inertia "i" holds the key to adequate deflection of the strut under impact load conditions. If "i $\mathrm{i}$ " is too large, the deflection is too low and the impact load factor is high; in other words, the gear is too stiff. The following calculations shows the effect of deflection on the design load factor. When developing a strut design it is necessary to vary strut dimensions $b$ and $h$ until sufficient deflection is obtained to provide acceptable vertical load factors, and hopefully without a too soft or "springy" gear.

The Maple V version 4 code (with results) for deflection and stress calculations follow:

$$
\begin{array}{lc}
\mathrm{W}:=2000 ; & \mathrm{b}:=5.775 \\
\mathrm{~W}:=2000 ; & \mathrm{h}:=1.2 ; \\
\mathrm{l}:=42 & \mathrm{~h}:=1.2 \\
1:=42 & \mathrm{i}:=\left(\mathrm{b}^{*} \mathrm{~h}^{\wedge} 3\right) / 12 ; \\
\mathrm{i}:=.8316000000 \\
\mathrm{E}:=10700000 ; & \theta:=22.5^{*}(3.142 / 180) ; \\
\mathrm{E}:=10700000 & \theta:=.3927500001 \\
\mathrm{~b}:=5.775 ; &
\end{array}
$$




$$
\begin{gathered}
\Delta:=\left(\left(2000 *(1)^{\wedge} 3\right) /\left(3 * \mathrm{E}^{*} \mathrm{i}\right)\right)^{*} \sec (\theta) ; \\
\Delta:=6.008307735
\end{gathered}
$$

So the deflection is a realistic six inches.

$$
\mathrm{TD}:=2.9
$$$$
\mathrm{TD}:=2.9
$$

$$
\begin{aligned}
\mathrm{d}:=(\Delta+\mathrm{TD}) / 12 ; \\
\mathrm{d}:=.7423589779
\end{aligned}
$$

$$
\begin{gathered}
\mathrm{Vd}:=4.4 *(2000 / 110)^{\wedge} .25 \\
\mathrm{Vd}:=9.085775552
\end{gathered}
$$

$$
\begin{aligned}
& \text { LVGDIF: }:=V^{\wedge} 2 /(2 * d) ; \\
& \text { LVGDIF }:=55.60067290
\end{aligned}
$$

$$
\begin{gathered}
\text { VDIF: }:=\text { LVGDIF } / 32.2 \\
\text { VDIF }:=1.726728972 \\
\begin{array}{c}
\eta=1.0+\text { VDIF; } \\
\eta
\end{array}=2.726728972 \\
\text { LDLF }:=\eta-0.67 ; \\
\text { LDLF }:=2.056728972
\end{gathered}
$$

Because FAR 23.473 (g) requires at least a $2 \mathrm{~g}$ limit design load factor, the landing gear limit design load factor (LDLF) just meets this criterion.

The final step was to take the CAD model of the landing gear and enter it into the Stardyne finite element modeling program for auto meshing and static and dynamic analysis. The version of Stardyne used was very full featured and relatively easy to use for a cost $\$ 3900$. The output is in the Appendix.

An additional simulation of the dynamics of the Berkut landing gear was attempted using Working Model version 2. In general, Working Model cannot model flexible bodies. However, Working Model can accurately simulate the motion of flexible beams by dividing the beam into discrete segments joined by springs with carefully chosen spring constants (Reckdahl, 1995). Unfortunately, because of the method of numeric integration employed in version 2 extremely long calculation times precluded obtaining simulations. Real-time simulations of the deflection of the landing gear were obtained using unrealistic parameters which are not discussed here. The most recent version of Working Model is reported to have improved numerical integration algorithms.

\section{Results}

The computer analysis of the F-16 synthesized a nose gear, which consisted of a shock strut, a two part drag brace and a single actuator. The dimensions for the simulated landing gear were taken from data supplied by Lockheed. Upon trying to replicate this gear, there was binding in two linkages that made up the drag brace. This problem was resolved by making small modifications to the geometry to make up for the 3-dimensional character of the actual gear which could not be reproduced with the 2-D version 2 of Working Model. The simulation was repeatedly rerun resulting eventually in smooth relative motion.

For the Berkut aircraft, "hand" calculations were performed for the bending stress using Maple $\mathrm{V}$. The results from the calculations showed that there would be highest bending stress at the root of the strut which is the top of the strut that attaches to the aircraft. The calculated stress was 86,309 psi, which exceeds the yield stress $(42,000 \mathrm{psi})$ of the aluminum material. The results of the finite element analysis were close to the Maple $\mathrm{V}$ calculations with a peak stress of 89,376 psi, (see Figure 7) with an average stress of 57,784 psi (see Figure 6). From the finite element analysis it appears that the stress is distributed longitudinally up the strut (see Figure 8). The maximum stress seems to be located in only a small portion of the top side corner of the root of the strut (see Figure 9). In addition to the bending stress, the Maple V calculations also showed that there would be a deflection of 6.008 inches for the landing gear and a landing gear design load factor of $2.05 \mathrm{~g}$. The actual Berkut uses stronger carbon fiber reinforced plastic composite material for the landing gear. Nearly all details of the construction of the gear are 
considered proprietary information by Experimental Aviation, Inc. An attempt to model the gear using carbon composite material was unsuccessful. While the Stardyne code is advertised to allow up to 45 plies of composite material, we were unable to get the program to accept more than 27 which was insufficient to model the gear.

\section{Conclusions}

Working Model software improves education for students by providing an easily constructed simulation of the behavior of the motion of the linkage comprising a front landing gear. It is difficult to visualize and analyze the retraction and extension processes and their relationship to component geometry in landing gear kinematics. The software makes it very easy evaluate velocity, acceleration and force quantitatively for a design by adding numeric or graphical output meters. The interface is graphic and intuitive.

The Stardyne finite element software allows the student to see the deflected shape of the maximally loaded Berkut main landing gear. It also provides the student a pictorial output for stress levels corresponding to the gear geometry analyzed. Here it is evident that high stress levels occurred in a very small area. The gear design should avoid sharp angles in this area, substituting smooth curves with radii big enough to reduce stress concentration. The deflection for the gear, even using aluminum material, satisfies the requirements set by FAR 23 for a $2 \mathrm{~g}$ landing load.

\section{References}

Cox, Jack, 1991, Berkut, Sport Aviation, December, pp. 52-59.

Currey, Norman S., 1988, Aircraft Landing Gear Design: Principles and Practice, AIAA Education Series, Washington, DC.

Experimental Aviation, Inc., Berkut Kit Airplanes, 3025 Airport Ave., Santa Monica, CA 90405. Knowledge Revolution, Inc., 1995, Working Model Version 2.0, Student Edition, Addison Wesley, New York, with Tutorials by Carol Rubin

Pazmany, Ladislao, 1986, Landing Gear Design For Light Aircraft Volume 1, and PL-8 Main Gear Design \& Trade-offs Pazmany Aircraft Corporation, San Diego, CA.

Puttman, Travis, 1995, Lockheed/Martin Tactical Aircraft Systems, Inc., private communication.

Raymer, Daniel P., 1992, Aircraft Design: A Conceptual Approach, AIAA Education Series, Washington, DC.

Reckdahl, Keith, undated, Working Model Technical Note: Modeling Uniform Flexible Bodies in Working Model, Knowledge Revolution, 1-800-766-6615.

Research Engineers, Inc., 1996, Stardyne Windows/NT Version, 22700 Savi Ranch, Yorba Linda, CA 92687-9943.

Thurston B. David., 1995, Design for Flying 2nd Edition, Tab Books, New York, NY.

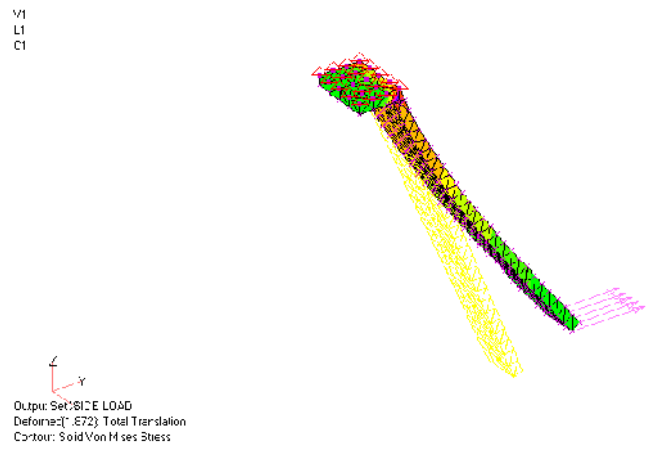

Figure 6
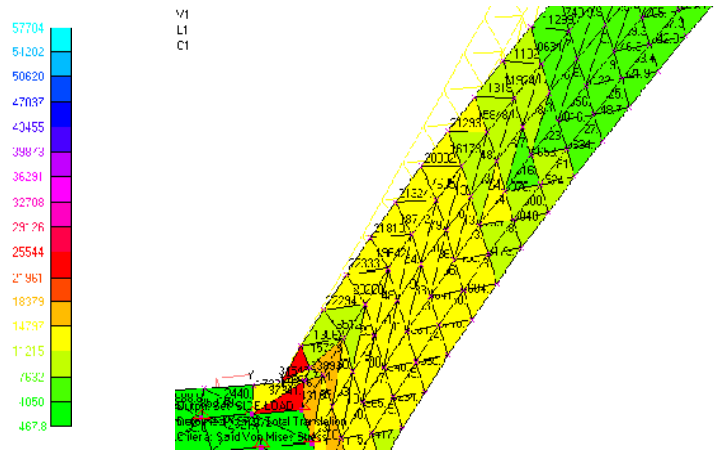

Figure 7 


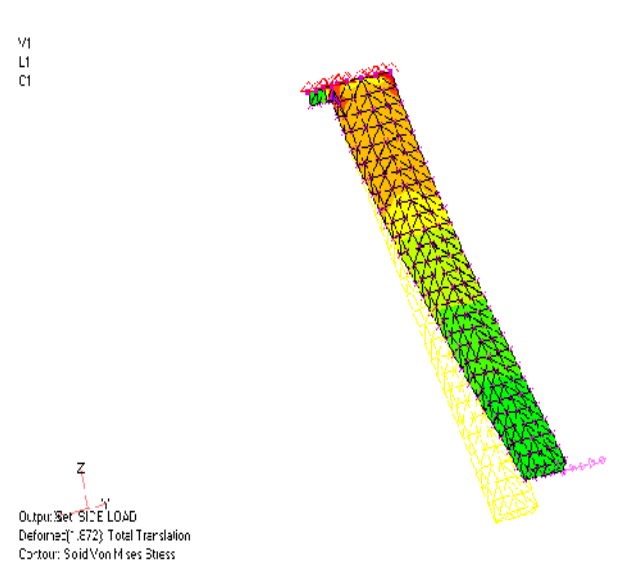

Figure 8

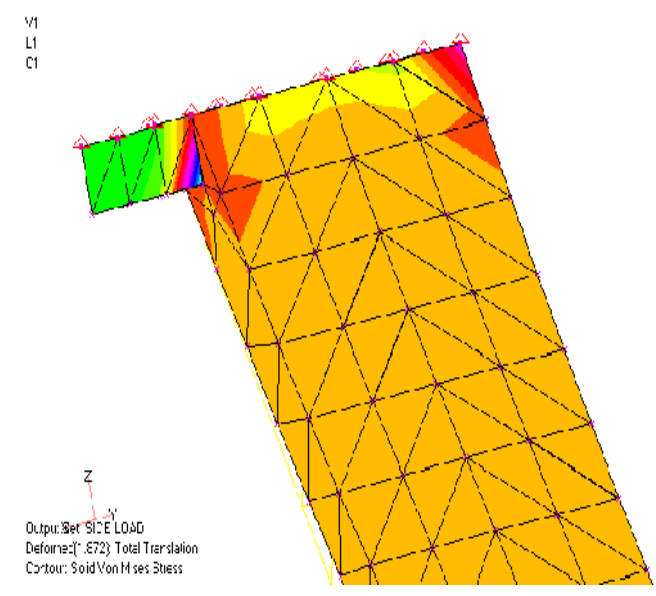

Figure 9

\section{Appendix -- Stardyne Output}

MAXIMUM STRESS SUMMARY FOR CUBES $\quad$ LOAD CASE NO.
MAXIMUM PRINCIPAL STRESS $=0.3902530 \mathrm{E}+05$ IN CUBE NO 1865
MINIMUM PRINCIPAL STRESS $=-0.6683470 \mathrm{E}+05$ IN CUBE NO 1782
MAXIMUM SHEAR STRESS $=0.5145041 \mathrm{E}+05$ IN CUBE NO 1782
MAXIMUM VONMISES VALUE $=0.8937632 \mathrm{E}+05$ IN CUBE NO 1782

\section{DEREK MORRISON}

Derek is a senior MET student at Purdue University Calumet and a McNair scholar. He formerly worked for IBM. He has presented three papers at the ASEE Illinois-Indiana Section meeting.

\section{GREGORY P. NEFF}

Gregory Neff is an associate professor of Mechanical Engineering Technology at Purdue University Calumet. He is a Registered Professional Engineer, a Certified Manufacturing Engineer, a Certified Manufacturing Technologist, and a Certified Senior Industrial Technologist. Greg is active in ASEE where he was one of the winners of the Meryl K. Miller award in 1994 and in SME where he is education \& certification chair for chapter 112 and faculty sponsor for student chapter 161. He is active in ASME, where he serves as MET Department Heads Committee Chair for Region VI and is an ASME TAC/ABET MET program evaluator. He is also a member of NAIT and the Order of the Engineer. His biography appears in recent Marquis Who's Who in Science and Engineering, Who's Who in America, Who's Who in the World, and Who's Who in Finance and Industry.

\section{MOHAMMAD A. ZAHRAEE}

Mohammad Zahraee is an associate professor of Mechanical Engineering Technology and chairman of the Department of Manufacturing Engineering Technologies and Supervision at Purdue University Calumet. He is a Registered Professional Engineer who received his Ph.D. in Theoretical and Applied Mechanics from the University of Illinois. Before joining Purdue Calumet he worked as an Engineering Specialist and Stress Analyst for a Chicago based consulting firm. Mohammad is active in ASEE where he was one of the winners of the Meryl K. Miller award in 1994. He is active in ASME, where he has served the MET Department Heads Committee in various offices including chair. A TAC/ABET MET program evaluator for four years, he currently is a member of the ASME Board on Engineering Education. 